Provided for non-commercial research and education use. Not for reproduction, distribution or commercial use.

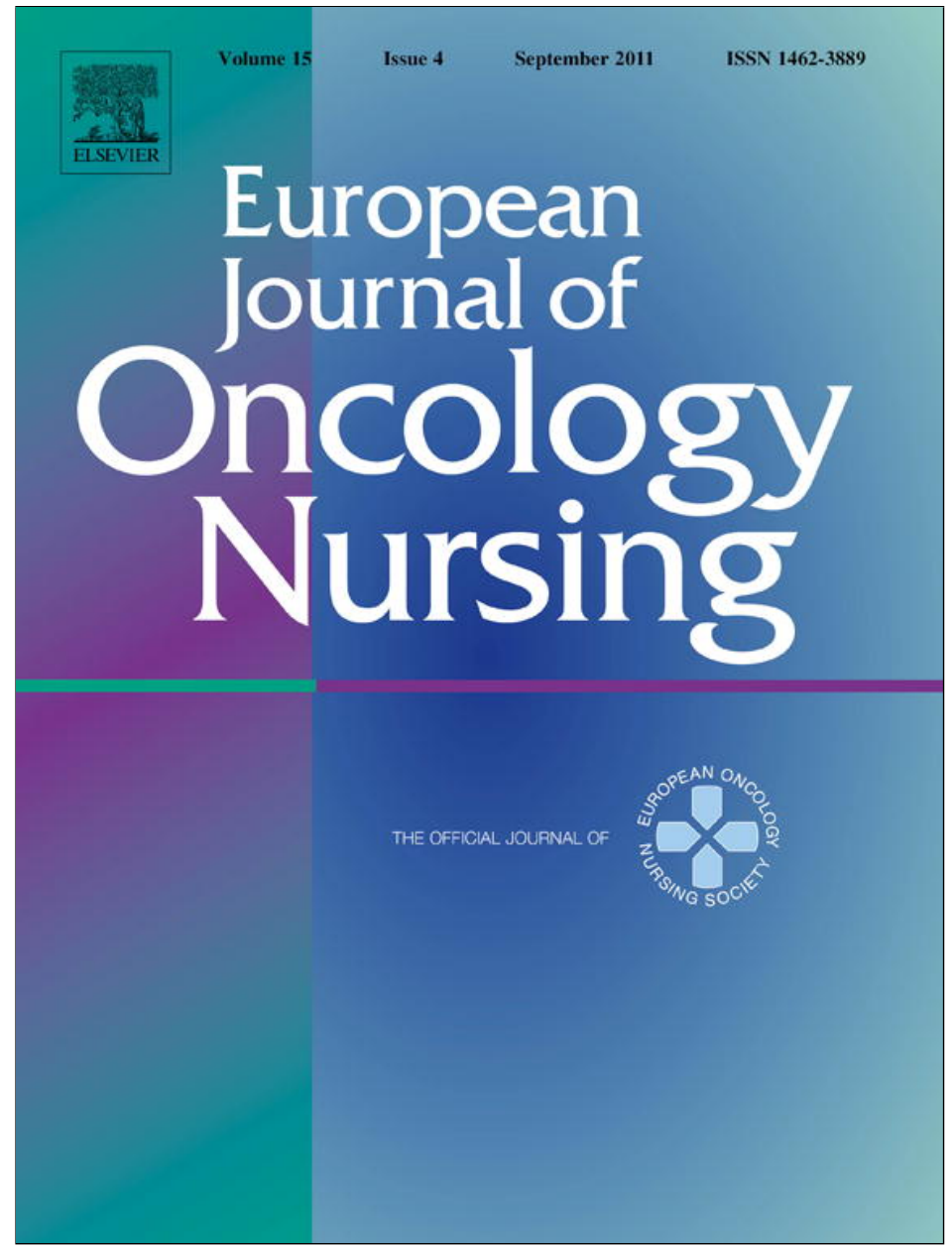

This article appeared in a journal published by Elsevier. The attached copy is furnished to the author for internal non-commercial research and education use, including for instruction at the authors institution and sharing with colleagues.

Other uses, including reproduction and distribution, or selling or licensing copies, or posting to personal, institutional or third party websites are prohibited.

In most cases authors are permitted to post their version of the article (e.g. in Word or Tex form) to their personal website or institutional repository. Authors requiring further information regarding Elsevier's archiving and manuscript policies are encouraged to visit:

http://www.elsevier.com/copyright 


\title{
Push or pull? Relationships between lung cancer patients' perceptions of quality of care and use of complementary and alternative medicine
}

\author{
M. Lövgren ${ }^{\mathrm{a}, \mathrm{b}, \mathrm{c}, *}$, B. Wilde-Larsson ${ }^{\text {d,e }}$, J. Hök ${ }^{\mathrm{f}}, \mathrm{H}_{\text {. Leveälahti }}{ }^{\mathrm{c}}, \mathrm{C}$. Tishelman ${ }^{\mathrm{a}, \mathrm{c}}$ \\ ${ }^{a}$ Dept. of Learning, Informatics, Management and Ethics, Medical Management Center, Karolinska Institutet, Stockholm, Sweden \\ ${ }^{\mathrm{b}}$ School of Health and Social Sciences, Dalarna University, Falun, Sweden \\ ${ }^{\mathrm{c}}$ Stockholms Sjukhem Foundation, Research \&' Development Unit/Palliative Care, Stockholm, Sweden \\ ${ }^{\mathrm{d}}$ Dept. of Nursing, Karlstad University, Karlstad, Sweden \\ ${ }^{\mathrm{e}}$ Dept. of Nursing, Hedmark University College, Elverum, Norway \\ ${ }^{\mathrm{f}}$ Dept. of Neurobiology, Caring Sciences and Society, Division of Nursing, Karolinska Institutet, Huddinge, Sweden
}

\section{Keywords:}

Quality of care

Complementary and alternative medicine

Lung cancer

Patient perspective

Complementary and alternative therapies

\begin{abstract}
A B S T R A C T
Little is known about relationships between quality of care (QoC) and use of complementary and alternative medicine (CAM) among patients with lung cancer (LC).

Purpose: This study examines CAM-use among patients with LC in Sweden, associations between QoC and CAM-use among these patients, and reported aspects of LC-care perceived as particularly positive and negative by patients, as well as suggestions for improving QoC.

Methods: Survey data from 94 patient members of the Swedish LC patient organization about CAM-use and QoC as measured by the instrument "Quality from the patient's perspective" were analyzed.

Results: Fifty (53\%) LC-patients used CAM, with 40 of the CAM-users reporting that CAM helped them. The most common CAMs used were dietary supplements and natural remedies, followed by prayer. Significantly more patients reported using prayer and meditation for cure than was the case for other types of CAM used. Less than half the CAM-users reported having spoken with staff from the biomedical health care system about their CAM-use. Patients provided numerous suggestions for improving LC-care in a variety of areas, aiming at a more effective and cohesive care trajectory. No differences in QoC were found between CAM-users and non-CAM-users, but differences in CAM-use i.e. type of CAM, reasons for using CAM, and CAM-provider consulted could be associated with different experiences of care. Conclusions: It is important to recognize that CAM-users are not a homogeneous group but might seek different types of CAMs and CAM-providers in different situations depending on experiences of care.
\end{abstract}

(c) 2010 Elsevier Ltd. All rights reserved.

\section{Introduction and aims}

Lung cancer (LC) is one of the most common cancer diagnoses and the most common cause of cancer death in Europe (Ferlay et al., 2010). The majority of patients with LC are diagnosed in late cancer stages and have a heavy symptom burden from diagnosis onward (Carlsen et al., 2005; Lövgren et al., 2008a,b; Oh, 2004). Even during the diagnostic workup, many patients are in need of palliation. Health care providers have to deal with patients' severe symptoms, including psychosocial concerns like uncertainty in illness (Berterö et al., 2008; Lövgren et al., 2010) and fear of death (Berterö et al.,

\footnotetext{
* Corresponding author. Stockholms sjukhem FoUU-enheten, Mariebergsgatan 22, 12219 Stockholm, Sweden. Tel.: +46(0)733302789; fax: +46861793 33 . E-mail address: mlv@du.se (M. Lövgren).
}

2008). Despite this high symptom burden and the multitude of relevant existential and psychosocial issues, in our previous work, we found that $27 \%$ of 343 patients with inoperable LC reported most distress from a problem related to their contact with the health care system (Tishelman et al., 2010).

There are few studies about quality of care (QoC) from LCpatients' perspective, with existent research on particular aspects of care. To date, focus has been on patients' perspectives of waiting time and time for encounters with health providers (Lövgren et al., 2009), communication of the LC diagnosis (Yardley et al., 2001), experiences in contact with health care providers (Salander and Henriksson, 2005), and satisfaction with doctor-patient communication (Gabrijel et al., 2008).

A different body of research indicates that dissatisfaction with care may predict increased use of complementary and alternative medicine (CAM) (Correa-Velez et al., 2003; Montazeri et al., 2007; Sirois and Gick, 2002). Vincent and Furnham (1996) describe such 
reasons for using CAM, as 'push factors', referring to factors driving patients away from biomedical health care. 'Pull factors', on the other hand, are described by the same authors as referring to those aspects of CAM which makes it attractive or compelling to patients. Despite the link between dissatisfaction with care and increased use of CAM, few studies have explored LC-patients use of CAM. While it is known that cancer patients report using more CAM than the general population (Mao et al., 2007), the prevalence varies from $7-83 \%$ in different studies (Ernst and Cassileth, 1998; Richardson et al., 2000). The only relevant European study found that approximately one quarter of LC-patients in eight European countries including Sweden, used CAM (Molassiotis et al., 2006). Given the limited knowledge in this area, and the suggestive findings to date, the aims of this explorative study are to examine: 1) CAM-use among patients with LC in Sweden, 2) associations between QoC and CAM-use among these patients, and 3) reported aspects of LC-care perceived as particularly positive and negative by patients, as well as their suggestions for improving QoC.

\section{Material and methods}

This explorative study is based on data from patients with LC who were recruited through the Swedish national LC-patient organization $^{1}$ (LCPO) which includes patients, family members and other interested persons in their membership. A letter containing two questionnaires, one for patients and one for family members, was sent to all registered members of LCPO in January 2007 $(N=351)$. A letter of support from the LCPO chairman, who was part of the research team, and an information letter from the principal investigator (CT) were included in the mailing. The questionnaires developed for this study primarily consisted of a study-specific version of the abbreviated instrument "Quality from the patient's perspective" (QPP) (Wilde Larsson and Larsson, 2002) supplemented with the brief quality of life instrument EQ5 (Rabin and de Charro, 2001), and with additional questions regarding CAM-use. Of the 351 registered members, 44 were deceased, 39 were supporting members and 9 questionnaires were returned to sender. We received a total of 189 responses of which 94 were from patients and 95 from family members. In this article, we focus on the data from patients only.

\section{Quality from the patient's perspective (QPP)}

The QPP is based on a theoretical model of QoC from a patient perspective (Wilde et al., 1993; Wilde Larsson and Larsson, 2002) developed from an initial grounded theory study (Wilde et al., 1993). The model stipulates that patients' perceptions of quality of care are formed by their encounters with an existing care structure and by their systems of norms, expectations, and experiences. QoC can be understood in light of two conditions; the resource structure of the care organization, consisting of personrelated, physical and administrative environment qualities, and patients' preferences. There are four dimensions of QoC within this framework: the medical-technical competence of the caregivers, the physical-technical conditions of the care organization, the degree of identity-orientation in the attitude and actions of the caregivers, and the socio-cultural atmosphere of the care organization. From this theoretical framework, the QPP was developed, tested and found to have robust psychometric characteristics (Larsson et al., 1998; Wilde et al., 1994) in a variety of settings and languages (Wilde Larsson et al., 2005), both in a full format and an

\footnotetext{
${ }^{1}$ The LCPO is called 'Stödet', literally meaning 'support' in Swedish.
}

abbreviated version (Larsson et al., 1998; Wilde Larsson and Larsson, 2002).

In the present study, we used an abbreviated QPP consisting of 21 items distributed by dimension as follows: medical-technical competence (3 items), physical-technical conditions ( 1 item), identity-orientation (12 items), and socio-cultural atmosphere (5 items). In addition, two items about telephone accessibility were included based on the recommendation of the LCPO chairman, acting as the patient representative in the research team. All items are shown in Table 1. Patients evaluated each item in two ways, in regard to "perceived reality" of QoC and "subjective importance". To measure perceived reality, each item (e.g. "I received useful information on the results on examinations and treatments") was evaluated on a four-point Likert scale ranging from 1 ("Do not agree at all") to 4 ("Fully agree") with an additional alternative for "not applicable". Subjective importance was assessed for the same item by responding to the statement "This is how important it was for me to receive..." (e.g. "useful information on the results on examinations and treatments"). A four-point Likert scale was used for these items ranging from 1 ("Of little or no importance") to 4 ("Of very great importance"), with an additional alternative for "not applicable".

The questionnaire ended with three open questions about experiences of LC-care: which aspects of care the patient perceived as particularly positive, which were perceived as negative, as well as suggestions for improving QoC.

\section{CAM-use}

In addition to the QPP, items about CAM-use were developed for this study based on previous work in this field (Hök, 2009). Questions were asked about reasons for using CAM (to promote health, increase well-being, cure disease, reduce side-effects from other treatments, and other reasons); type of CAM-provider consulted (physician, nurse or physiotherapist; caregivers outside the biomedical health care system; other caregivers; self-care) and type of CAM used. Based on previous national and international CAM surveys (Hanssen et al., 2005; Molassiotis et al., 2005) and the well established categorization system described by National Center for Complementary and Alternative Medicine (NCCAM, 2010), we asked specifically about use of twelve types of CAM (i.e. natural remedies, vitamins and minerals, healing, qi gong, massage, acupuncture, naprapathy, chiropractic care, anthroposophic medicine, homeopathy, meditation, prayer). This covered a range of different CAM, from systems (e.g. anthroposophic medicine) to specific therapies (e.g. biologically-based therapies) (NCCAM, 2010). Space was also provided for reporting other types of CAM-use.

In addition, patients were asked to respond to two CAM-items: "I feel that this (CAM) method(s) helped me", and "I discussed my use of these CAM with staff in the conventional health care system", in terms of both perceived reality and subjective importance, using the previously described response alternatives.

\section{Data analysis}

\section{Demographic and clinical characteristics}

Demographic and clinical characteristics were examined with descriptive statistics. Potential differences between CAM-users and non-CAM-users were tested with $\chi^{2}$-test (gender, civil status, occupational status, educational level), independent sample $t$-test (age), and Mann-Whitney $U$-test (time in months from diagnosis to data collection). 
Table 1

Mean value and standard deviation (SD) for the dimensions (identity-oriented approach and socio-cultural atmosphere) and items in QPP. Dimensions with mean values are shown in bold text.

\begin{tabular}{|c|c|c|}
\hline Dimensions and items & $\begin{array}{l}\text { Perceived reality of QoC } \\
\text { Mean value (SD) }\end{array}$ & $\begin{array}{l}\text { Subjective importance } \\
\text { Mean value (SD) }\end{array}$ \\
\hline Medical-technical conditions $^{\mathrm{a}}$ & - & - \\
\hline I received the best possible medical examination and treatment & $3.49(0.80)$ & $3.89(0.32)$ \\
\hline I received effective pain relief & $3.31(1.03)$ & $3.82(0.42)$ \\
\hline I received examinations and treatment within acceptable waiting times & $3.28(0.87)$ & $3.31(0.78)$ \\
\hline Identity-oriented approach & $3.10(0.76)$ & $3.6(0.39)$ \\
\hline I received useful information on the results on examinations and treatments & $3.07(0.96)$ & $3.76(0.43)$ \\
\hline I received useful information on which doctor were responsible for my medical care & $2.98(1.20)$ & $3.63(0.59)$ \\
\hline I received useful information on how examinations and treatments would take place & $3.31(0.90)$ & $3.60(0.63)$ \\
\hline I received useful information on self-care; 'how I should take care of myself' & $2.60(1.17)$ & $3.40(0.77)$ \\
\hline I received useful information on which nurse were responsible for my nursing care & $2.67(1.28)$ & $3.34(0.76)$ \\
\hline The doctors showed commitment; 'cared about me' & $3.26(0.98)$ & $3.74(0.47)$ \\
\hline The doctors seemed to understand how I experienced my situation & $3.20(0.97)$ & $3.73(0.47)$ \\
\hline The nurses and assistant nurses seemed to understand how I experienced my situation & $3.36(0.81)$ & $3.64(0.53)$ \\
\hline The doctors were respectful towards me & $3.50(0.79)$ & $3.70(0.53)$ \\
\hline The nurses and assistant nurses showed commitment; 'cared about me' & $3.38(0.84)$ & $3.67(0.52)$ \\
\hline The nurses and assistant nurses were respectful towards me & $3.45(0.81)$ & $3.61(0.58)$ \\
\hline I have good opportunity to participate in the decisions that applied to my care & $2.68(1.20)$ & $3.54(0.65)$ \\
\hline Physical-technical conditions ${ }^{\mathrm{a}}$ & - & - \\
\hline I had access to the apparatus and equipment that was necessary for my medical care (as far as I can tell) & $3.56(0.70)$ & $3.71(0.57)$ \\
\hline Socio-cultural conditions & $3.20(0.68)$ & $3.50(0.48)$ \\
\hline My relatives and friends were treated well & $3.39(0.81)$ & $3.57(0.57)$ \\
\hline My care was determined by my own request and needs rather than the staff's procedures & $2.75(1.02)$ & $3.48(0.65)$ \\
\hline There was a pleasant atmosphere on the ward & $3.02(0.94)$ & $3.35(0.71)$ \\
\hline I talked to the nurses in private when I wanted to & $3.31(0.89)$ & $3.26(0.82)$ \\
\hline I talked to the doctors in private when I wanted to & $3.41(0.86)$ & $3.54(0.63)$ \\
\hline Telephone accessibility ${ }^{\mathrm{a}}$ & - & - \\
\hline It was easy to reach the health care by phone (non-office hours) & $2.57(1.19)$ & $3.71(0.46)$ \\
\hline It was easy to reach the health care by phone (day time) & $2.87(1.10)$ & $3.56(0.57)$ \\
\hline
\end{tabular}

${ }^{a}$ No mean value for this dimension was calculated as Cronbach's alpha was too low.

\section{CAM-use (aim 1)}

Descriptive statistics were used to examine patients' CAM-use (type of CAM, reasons for using CAM, CAM-provider and communication with biomedical health care providers about CAM-use) and $\chi^{2}$-tests were used to examine relationships between different aspects of patients' CAM-use.

\section{Cronbach's alpha for QPP}

The Cronbach's alpha for the QPP dimensions was 0.91 (perceived reality of $\mathrm{QoC}) / 0.83$ (subjective importance) for identityorientation, $0.44 / 0.36$ for medical-technical competence, $0.66 /$ 0.59 for socio-cultural atmosphere and $0.49 / 0.48$ for telephone accessibility. These results underlay a decision to only calculate mean values for the dimensions identity-orientation and sociocultural atmosphere. No Cronbach's alpha was calculated for physical-technical conditions as only one item was included in that dimension.

The association between perceived QoC and CAM-use (aim 2)

When an item was missing within a QPP-dimension in a patient's response, no mean value was calculated for that patient. Descriptive statistics were used to analyze each QPP item in the dimensions medical-technical competence and physical-technical conditions, as well as items on telephone accessibility.

To examine potential differences between CAM-users and nonCAM-users regarding QoC (perceived reality and subjective importance), Mann-Whitney $U$-tests were conducted. Analyses were conducted for the dimensions identity-orientation and socio-cultural atmosphere, and on the item level for medical-technical competence, physical-technical conditions and telephone accessibility.

Mann-Whitney $U$-tests were used to examine potential differences within the group of CAM-users regarding QoC (perceived reality and subjective importance) in relation to type of CAM, reasons for using CAM, type of CAM-provider, and communication with biomedical health care providers about CAM-use. Spearman's correlations were used to examine potential associations between QoC (perceived reality of care) and the extent to which the patients talked to biomedical health care providers about their CAM-use. Again, analyses for identity-orientation and socio-cultural atmosphere were conducted by dimensions, whereas medical-technical competence, physical-technical conditions and telephone accessibility were examined by item.

The level for statistical significance was set at $\leq 0.05$ in all tests.

Analysis of open questions (aim 3)

To analyze the patients' statements about what they perceived as positive and negative in their contact with the health care, as well as their suggestions for improvement, the patients' statements were coded into categories based on similarity in content. This was done by two authors (ML, BW-L) first coding each statement separately, then comparing their individual coding, and negotiating consensus around the few differences in interpretation. Finally, another author (CT) reviewed the coding scheme, with no substantial differences found in interpretation. To examine if there were areas of importance reported outside the scope of QPP, all statements were also evaluated in relation to the items and dimensions in QPP as: 1) included, or 2) not included in QPP.

\section{Results}

\section{Demographic and clinical characteristics}

As shown in Table 2, the mean age of the respondents was 62 years, with the majority retired and living with a partner. There were no statistically significant differences between CAM-users and non-CAM-users regarding age, gender, occupational status, civil status, educational level, and time from diagnosis to data collection (Table 2). 
Table 2

Demographic and clinical characteristics of the participants.

\begin{tabular}{|c|c|c|c|c|}
\hline & $\begin{array}{l}\text { Total } \\
(N=92)\end{array}$ & $\begin{array}{l}\text { Non-CAM-users } \\
(N=42) \\
45.7 \%\end{array}$ & $\begin{array}{l}\text { CAM-users } \\
(N=50) \\
54.3 \%\end{array}$ & $p$-value \\
\hline Age & & & & 0.063 \\
\hline Median & 62.0 & 64.5 & 61.0 & \\
\hline Mean (SD) & $62.3(10.0)$ & $64.7(8.4)$ & $60.4(10.9)$ & \\
\hline Min-max & $30-80$ & $37-80$ & $30-80$ & \\
\hline Missing & 15 & 8 & 7 & \\
\hline \multicolumn{4}{|c|}{ Time in months from diagnosis to data collection } & 0.132 \\
\hline Median & 26.0 & 20.0 & 31.0 & \\
\hline Mean (SD) & $40.4(59.9)$ & $42.9(82.2)$ & $38.4(31.7)$ & \\
\hline Min-max & $2-507$ & $3-507$ & $2-149$ & \\
\hline Missing & 2 & 1 & 1 & \\
\hline Gender & & & & 0.757 \\
\hline Men & $27(29.3)$ & $13(31.0)$ & $14(28.0)$ & \\
\hline Women & $65(70.7)$ & $29(69.0)$ & $36(72.0)$ & \\
\hline Occupational status & & & & 0.540 \\
\hline Employed & $31(33.7)$ & $13(31.0)$ & $18(36.0)$ & \\
\hline Pensioner & $53(57.6)$ & $26(61.9)$ & $27(54.0)$ & \\
\hline Other & $7(7.6)$ & $2(4.8)$ & $5(10.0)$ & \\
\hline Missing & $1(1.1)$ & $1(2.4)$ & $0(0.0)$ & \\
\hline Civil status & & & & 0.673 \\
\hline $\begin{array}{l}\text { Lived together } \\
\text { with a partner }\end{array}$ & $57(62.0)$ & $27(64.3)$ & $30(60.0)$ & \\
\hline Lived alone & $35(38.0)$ & $15(35.7)$ & $20(40.0)$ & \\
\hline Educational level & & & & 0.157 \\
\hline$<$ High school & $16(17.4)$ & $7(16.7)$ & $9(18.0)$ & \\
\hline $\begin{array}{l}\text { High school or } \\
\text { equivalent (12 yrs) }\end{array}$ & $33(35.9)$ & $20(47.6)$ & $13(6.0)$ & \\
\hline $\begin{array}{l}\text { University/University } \\
\text { College }\end{array}$ & $36(39.1)$ & $12(28.6)$ & $24(48.0)$ & \\
\hline Other education & $2(2.2)$ & $1(2.4)$ & $1(2.0)$ & \\
\hline Missing & $5(5.4)$ & $2(4.8)$ & $3(6.0)$ & \\
\hline
\end{tabular}

\section{LC-patients' CAM-use (aim 1)}

Fifty (53\%) of the 92 patients who responded to this question reported that they used CAM, with an average of 1.8 different CAMs each (median value: 1, min-max: 1-8). Eight patients reported using three or more CAMs. As shown in Table 3, the most common CAMs were biologically-based therapies (i.e. dietary supplements and natural remedies), followed by mind-body therapies, particularly prayer.

Table 3

Type of CAM-use among patients with LC. More than one CAM can be used.

\begin{tabular}{ll}
\hline Type of CAM & $\mathrm{N}(\%)$ \\
& $50(100)$ \\
\hline Biologically-based therapies: & $25(50)$ \\
Dietary supplements & $21(42)$ \\
Natural remedies ${ }^{\mathrm{a}}$ & $10(20)$ \\
Energy therapies: & $4(8)$ \\
Healing & $3(6)$ \\
Qi gong & $1(2)$ \\
Manipulative- and Body-based therapies: & $13(26)$ \\
Massage & $12(24)$ \\
Acupuncture & $2(4)$ \\
Naprapathy (a manual therapy) & $1(2)$ \\
Chiropractice care & 0 \\
Alternative medical systems: & $10(20)$ \\
Antroposophic medicine & $9(18)$ \\
Homeopathy & $2(4)$ \\
Mind-body therapies: & $19(38)$ \\
Meditation & $4(8)$ \\
Prayer & $16(32)$ \\
Other type of CAM-methods than above & $10(20)$ \\
\hline
\end{tabular}

\footnotetext{
a Two Swedish terms with differing legal status used in the question: Natur-
} läkemedel/Naturmedel.
The statement that CAM helped them was endorsed fully by 19 patients, mostly by seven and partly by 14 with only one of the 41 patients who responded to the question disagreeing with this statement. This statement was reported to be of great importance by 20 patients, of much importance by eleven patients, of some importance by ten patients, and of little or no importance by one of the 42 responding patients.

CAM use was most often reported for health promotion $(n=33)$. Twenty of the 50 users said their CAM-use was intended to increase well-being, 14 patients said use was to cure disease and seven used CAM to reduce side-effects from other treatments. Additional reasons reported for using CAM $(n=10)$ included for social/existential/spiritual needs, pain relief, to increase the effects of chemotherapy, to improve blood values, maintain weight and improve lung capacity. Significantly more patients reported using mind-body therapies for cure than was the case for other types of CAM $(p=0.02)$. Significantly more patients reported using biologically-based therapies to promote health than was the case for other types of CAM used $(p=0.02)$.

Fifteen patients reported receiving CAM from physicians, nurses or physiotherapists, with eight patients reporting receiving CAM from caregivers outside the biomedical health care system, and four from other caregivers. Thirty patients reported obtaining CAM themselves, with 22 of those using CAM for self-care without professional mediation. Significantly more patients who used manipulative- and body-based therapies consulted a physician, nurse or physiotherapist than did patients reporting other types of CAM-use $(p=0.011)$.

Twenty-one patients who reported CAM-use also reported having spoken with biomedical health care providers about this (data missing from 13 CAM-users). Twelve patients fully agreed that they had spoke to the biomedical health care providers, nine endorsed the middle alternatives and partly agreed, four did not agree at all, and twelve patients reported that the statement not was applicable. The subjective importance for this item was reported as of the greatest importance by nine patients, of much importance by 11 and of some importance by three patients, with four reporting it to be of little or no importance; 12 patients responded that the question was "not applicable" (data missing from 11 CAM-users).

The association between perceived QoC and CAM-use (aim 2)

Mean values for perceived reality and subjective importance of QoC are shown in Table 1. No differences in QoC were found between CAM-users and non-CAM-users.

\section{Differences in perceived QoC among CAM-users}

\section{Perceived reality of $\mathrm{QoC}$}

Patients who reported using anthroposophic medicine and/or homeopathy were found to have lower perceived reality of QoC regarding the best possible medical examination and treatment $(p=0.003)$ and identity-oriented approach $(p=0.021)$ than those patients reporting use of any other type of CAMs.

Patients who reported using CAM for health promotion reported lower perceived reality of QoC regarding identity-oriented approach $(p=0.035)$ than did those who used CAM for other reasons.

Patients who reported that their CAM-provider was a physician, nurse or physiotherapist were found to perceive lower reality of QoC regarding the best possible medical examination and treatment $(p=0.003)$, effective pain alleviation $(p=0.022)$, waiting time $(p=0.011)$, telephone accessibility both during office hours $(p<0.001)$ and non-office hours $(p=0.001)$ than those receiving 
CAM from other sources. Patients who received CAM from a caregiver outside the biomedical health care system perceived lower reality of QoC regarding the best possible medical examination and treatment $(p<0.001)$, socio-cultural atmosphere $(p=0.017)$, and telephone accessibility during non-office hours $(p=0.014)$ in comparison with those receiving CAM from other sources.

No statistically significant correlation was found between perceived reality of QoC and the extent to which patients discussed their CAM-use with biomedical health care providers.

\section{Subjective importance}

The group of patients reporting using meditation and prayer reported higher subjective importance regarding the best possible medical examination and treatment $(p=0.031)$ and identityoriented approach $(p=0.04)$ in comparison with those patients using other CAMs. Patients who used biologically-based therapies reported lower subjective importance of socio-cultural atmosphere $(p=0.034)$ in comparison with patients who used other therapies.

\section{Patients' experiences of care and their suggestions for improvement (aim 3)}

Most positive and negative statements regarding LC-care were related to the dimensions identity-oriented approach, followed by medical-technical conditions (Table 4). Patients' suggestions for improvement related to items in the QPP regarded establishment of a rehabilitation program, shorter waiting times, improved medical treatment, improved quality of psychosocial care, need for one doctor/nurse responsible for coordinating care, improved written and oral information, and more modern and/or renovated physical environments. Statements not related to QPP focused on continuity of care including care between and beyond medical treatments, i.e. accessibility to health care providers, coordination of services, a need for patient support groups, and a desire for health care providers to be more positive and foster hope in patients (Table 4).

\section{Discussion}

Fifty-three percent $(N=50)$ of these LC-patients used CAM, with 40 of 50 of the CAM-users reporting that CAM helped them. Major reasons given by patients for using CAM included: health promotion, increased well-being, as well as for curing disease and reducing side-effects of other treatments. The included patients used a wide variety of CAMs, including dietary supplements and natural remedies, massage, acupuncture and prayer. Significantly more patients reported using prayer and meditation for cure than was the case for other types of CAM used. Also, significantly more patients reported using dietary supplements and natural remedies to promote health compared to patients using other types of CAM. Less than half of the CAM-users in this study reported that they had spoken with biomedical health care staff about their CAM-use. Patients provided numerous suggestions for improving LC-care in a variety of areas, from a more effective and cohesive care trajectory including better psychosocial care, to establishment of

Table 4

Patents' reported experiences of LC-care and their suggestions for improvements. The relationship between the patients' statements and the QPP dimensions is also shown.

\begin{tabular}{|c|c|c|}
\hline Dimensions in QPP & Positive experiences & Negative experiences \\
\hline $\begin{array}{l}\text { Medical-technical } \\
\text { conditions }\end{array}$ & $\begin{array}{l}\text { Good medical treatment, including no } \\
\text { distress and effective treatment } N=7 \\
\text { No waiting times, } N=5 \\
\text { Staff knowledge and competence, } N=5\end{array}$ & $\begin{array}{l}\text { No rehabilitation, } N=1 \\
\text { Long waiting times, } N=9 \\
\text { Poor medical treatment, } \\
\text { including side-effects of treatment, } \\
\text { poor pain relief, age as a reason for } \\
\text { choice of treatment method, } \\
\text { delayed diagnosis, } N=11\end{array}$ \\
\hline $\begin{array}{l}\text { Identity-oriented } \\
\text { approach }\end{array}$ & $\begin{array}{l}\text { Pleased with how they were treated } \\
\text { by staff: positive encounters with staff, } \\
\text { kindness, empathy, respect, engagement, } \\
\text { sense of trust, } N=34 \\
\text { Pleased with having one responsible } \\
\text { doctor/nurse, } N=7 \\
\text { Good information, } N=6\end{array}$ & $\begin{array}{l}\text { Displeased with how they were } \\
\text { treated by staff: no sense of empathy, } \\
\text { do not feel safe, no sense of staff } \\
\text { engagement, impersonal care, } N=6 \\
\text { Poor continuity of care without one } \\
\text { responsible doctor/nurse, } N=6 \\
\text { Poor information, } N=7\end{array}$ \\
\hline
\end{tabular}

Suggestions for improvement

Establishment of a rehabilitation program, $N=2$

Shorter waiting times, $N=5$

Need for improved medical treatment, including the same treatment regardless of age, performance status, responsible doctor, etc., $N=1$

Improved quality of psychosocial care, including encounters with staff, more empathy, kindness, understanding, more 'personal care', $N=11$

Need for continuity of care with one responsible doctor/nurse, $N=9$

More information, more concrete information and more written material about $(N=7)$ :

- Treatments/Medications

- Rehabilitation

- Side-effects

- Home care

- Nutrition

Physical-technical conditions

Socio-cultural conditions Telephone accessibility

Not included in QPP
Pleasant physical environment in the treatment room, $N=1$ Single room, $N=1$

Pleasant atmosphere on the ward, $N=2$ Good telephone contact with staff between the health care visits, $N=2$ Good accessibility to the health care system or to nurses, $N=4$ Good coordination of care including good logistics, $N=1$
Basic needs not satisfied, including hygiene and food, $N=2$ Dissatisfied with patient rooms and equipment, $N=5$

Hard to reach health providers, $N=3$

Poor accessibility to doctors, $N=4$

Bad coordination of care and poor logistics, $N=3$

No sense of hope conveyed from staff, $N=1$

No care between medical treatments, $N=2$
More modern and/or renovated physical environment, including more and larger rooms, bathrooms for each room, TV in each room, popular magazines in the waiting room, $N=10$

Telephone time with doctors, $N=1$

Improved accessibility to nurses and doctor, $N=5$

Improved coordination of care, $N=3$

Staff that conveys hope, $N=2$

Form patient support groups, $N=1$

More time with doctors, $N=2$ 
a rehabilitation program. This study also indicated that differences in CAM-use i.e. type of CAM, reasons for using CAM, and CAMprovider consulted could be associated with different experiences of care.

This study found that these patients with LC used CAM to a greater extent than previously described in Molassiotis et al.'s (2006) European study. The prevalence of CAM-use noted here is similar to that found among palliative patients in Australia (CorreaVelez et al., 2003) and patients with LC in US (Saydah and Eberhardt, 2006). These differences in prevalence of CAM-use might be due to differences in measuring CAM, but may also relate to other study characteristics, for example it might be that members of a patient organization who responded here may generally be more pro-active than other LC-patients.

As noted previously, Vincent and Furnham (1996) have distinguished "push factors" as those that drive patients away from the biomedical health care, whereas "pull factors" relate to aspects of CAM which makes it attractive or compelling to patients. In this study, we were interested in whether push factors could be related to perceived QoC. In line with previous studies [see e.g. (Kelner and Wellman, 1997)], we found more differences within the group of CAM-users than between CAM-users and non-CAM-users, making this factor alone insufficient to explain patients' CAM-use. Pull factors, instrumentalized here as reasons for using CAM (e.g. to promote health and well-being), in conjunction with most patients reporting benefit from their CAM-use, might therefore be important aspects motivating patients' CAM-use. The accessibility of treatment found with CAM and hope for control over their own treatment (Adams and Jewell, 2007) might also have influenced patients' CAM-use, as these aspects were reported by patients as lacking in present biomedical care, but viewed as important for their LC-care.

The reasons for using CAM described in this study are in line with results from a qualitative study by Thorne, et al. (2002). They found that CAM-users with chronic diseases took responsibility for their own health by using CAM to relieve symptoms, promoting health and increasing healing. In contrast to Thorne, et al. (2002) who found that CAM-use not was related to a search for cure, we found that $14(28 \%)$ of these LC-patients reported using CAM in an effort to cure LC, which is in line with the results from Molassiotis et al. (2006). Kronenbergh and Mindes (2005) suggest that individuals with advanced cancers use CAM as curative treatment to a greater extent than individuals with early stages of cancer, which might provide one explanation for this finding. The relationship between prayer/meditation and cure found in this study might indicate that these patients are in greater need of hope for cure than is offered by the biomedical health care system, as hope was reported by patients to be lacking in the conventional care. The importance of hope for these patients is also evidenced by the relatively high prevalence of prayer in these patients from Sweden, which is a very secular country. What hope means for the patients in this study is unclear, with different meanings of hope highlighted in the literature (Ezzy, 2000). Barnard (1995) distinguishes two types of hope for persons with chronic illnesses. Barnard's term (1995) "concrete hope" relates to a specific outcome, e.g. a hope that treatment will cure the disease, whereas "transcendent hope" is not associated with achieving a goal, but rather with finding new ways of experiencing time and reality (Barnard, 1995). As many types of CAMs are advertised as curative cancer treatments (Schmidt and Ernst, 2004), it might be of importance to distinguish between concrete and transcendent hope. Transcendent hope might function as a means to manage the complexities of LCpatients' illness experiences and therefore be an important aspect to consider in LC-care. This issue points a need for stringent research about efficacy and safety in CAM-use.
In contrast to earlier research about gender differences in CAMuse (Molassiotis et al., 2005; Richardson et al., 2000), no differences in CAM-use among women and men were found in this study. One possible reason for these contradictory research results might be related to the group studied as well as differences in how men and women respond to symptoms. Fouladbakhsh and Stommel (2010) found that male cancer patients' symptom experiences appear to act as a stronger trigger for CAM-use than is the case for women. They mean that one possible reason for this might be that men may tend to seek a solution to their problem to a greater extent than do women when reporting symptoms. As LC-patients report both more and more severe symptoms than other cancer patients, men with LC might tend to use CAM to a greater extent than other male cancer patients less burdened by symptoms.

Even if patients in this study reported perceiving relatively good QoC on the QPP, they reported poorer perceived reality of QoC than has been found in other patient groups in Sweden, e.g. advanced home care which primarily included patients with cancer, patients in primary health care (Wilde-Larsson and Larsson, 2009), and patients undergoing ostomy surgery (Persson and Wilde Larsson, 2005). However, these LC-patients reported better perceived reality of QoC than did women who received an abnormal Pap smear after attending population-based screening (Tishelman et al., 2002). Aspects related to poorer perceived reality of QoC in this study were associated with poor continuity of care, poor coordination of services, and poor accessibility to health care providers. Similar complaints have been found by Lövgren et al. (2010) in a different group of LC-patients in Sweden. They found that patients related such deficiencies in the health care system to the health care system's lack of and poor prioritization of time for patient contact. Temporal aspects were also explicit in this study as patients suggested shorter waiting times and more time with health care professionals as important for improving LC-care. Issues like these which are beyond the scope of the QPP but spontaneously addressed by patients might need to be considered in future QoC measurement in LC-patients, and perhaps also for other patient groups.

This study contributes to a deeper understanding of LC-patients' CAM-use, although given the relatively small sample size the relationship between CAM-use and QoC should be further explored. The study results indicate that health care professionals need to be aware that CAM-users are not a homogeneous group but might seek different types of CAM and/or CAM-providers in different situations depending on their experiences of care. It might also be important to consider the function of hope in LC-care. The lack of communication between patients and biomedical health professionals about CAM found in this study limits opportunities to discuss potential benefits and risks in CAM-use. Richardson et al. (2004) mean that oncologists and cancer patients hold discrepant views of CAM, which may contribute to a communication gap between biomedical providers and patients. Further research should be conducted about how LC-care can be improved according to patients' recommendations and needs.

\section{Conflict of interest statement}

No potential conflicts of interest.

\section{Acknowledgement}

Funding for this project has been gratefully received from The Swedish Cancer Nursing Society. We also want to acknowledge that this project was initiated by the late Anders Jonasson, then chairman of the LC-patient organization in Sweden. We are grateful for the opportunity to have collaborated with him, and with the LCpatient organization. 


\section{References}

Adams, M., Jewell, A.P., 2007. The use of complementary and alternative medicine by cancer patients. International Seminars in Surgical Oncology 4, 10.

Barnard, D., 1995. Chronic illness and the dynamics of hoping. In: Toombs, S., Barnard, D., Carson, R. (Eds.), Chronic illness: from Experience to Policy. Indiana University Press, Bloomington.

Berterö, C., Vanhanen, M., Appelin, G., 2008. Receiving a diagnosis of inoperable lung cancer: patients' perspectives of how it affects their life situation and quality of life. Acta Oncologica 47 (5), 862-869.

Carlsen, K., Jensen, A.B., Jacobsen, E., Krasnik, M., Johansen, C., 2005. Psychosocial aspects of lung cancer. Lung Cancer 47 (3), 293-300.

Correa-Velez, I., Clavarino, A., Barnett, A.G., Eastwood, H., 2003. Use of complementary and alternative medicine and quality of life: changes at the end of life. Palliative Medicine 17 (8), 695-703.

Ernst, E., Cassileth, B.R., 1998. The prevalence of complementary/alternative medicine in cancer: a systematic review. Cancer 83 (4), 777-782.

Ezzy, D., 2000. Illness narratives: time, hope and HIV. Social Science \& Medicine 50 (5), 605-617.

Ferlay, J., Parkin, D.M., Steliarova-Foucher, E., 2010. Estimates of cancer incidence and mortality in Europe in 2008. European Journal of Cancer 46 (4), 765-781.

Fouladbakhsh, J.M., Stommel, M., 2010. Gender, symptom experience, and use of complementary and alternative medicine practices among cancer survivors in the U.S. cancer population. Oncology Nursing Forum 37 (1), E7-E15.

Gabrijel, S., Grize, L., Helfenstein, E., Brutsche, M., Grossman, P., Tamm, M., Kiss, A., 2008. Receiving the diagnosis of lung cancer: patient recall of information and satisfaction with physician communication. Journal of Clinical Oncology 26 (2), 297-302.

Hanssen, B., Grimsgaard, S., Launso, L., Fonnebo, V., Falkenberg, T., Rasmussen, N.K., 2005. Use of complementary and alternative medicine in the Scandinavian countries. Scandinavian Journal of Primary Health Care 23 (1), 57-62.

Hök, J., 2009. Use of Complementary and alternative medicine in the context of cancer. Perspectives on exceptional experiences. In: The Dept of Neurobiology, Care Sciences and Society, The Division of Nursing, Unit for Studies of Integrative Care, PhD thesis. Karolinska Institutet, Stockholm.

Kelner, M., Wellman, B., 1997. Who seeks alternative health care? A profile of the users of five modes of treatment. Journal of Alternative \& Complementary Medicine 3 (2), 127-140.

Kronenberg, F., Mindes, J., 2005. The Future of complementary and alternative medicine for cancer. Cancer Investigation 23, 420-426.

Larsson, G., Wilde Larsson, B., Munck, I.M., 1998. Refinement of the questionnaire 'quality of care from the patient's perspective' using structural equation modelling. Scandinavian Journal of Caring Sciences 12 (2), 111-118.

Lövgren, M., Levealahti, H., Tishelman, C., Runesdotter, S., Hamberg, K., 2008a. Time spans from first symptom to treatment in patients with lung cancer-the influence of symptoms and demographic characteristics. Acta Oncologica 47 (3), $397-405$.

Lövgren, M., Tishelman, C., Hamberg, K., 2010. Clock time and embodied time among patients with inoperable lung cancer. Cancer Nursing 3 (1), 55-63.

Lövgren, M., Tishelman, C., Sprangers, M., Koyi, H., Hamberg, K., 2008b. Symptoms and problems with functioning among women and men with inoperable lung cancer-a longitudinal study. Lung Cancer 60 (1), 113-124.

Mao, J.J., Farrar, J.T., Xie, S.X., Bowman, M.A., Armstrong, K., 2007. Use of complementary and alternative medicine and prayer among a national sample of cancer survivors compared to other populations without cancer. Complementary Therapies in Medicine 15 (1), 21-29.

Molassiotis, A. Fernadez-Ortega, P. Pud, D. Ozden, G., Scott, J.A., Panteli, V., Margulies, A., Browall, M., Magri, M., Selvekerova, S., Madsen, E., Milovics, L., Bruyns, I., Gudmundsdottir, G., Hummerston, S., Ahmad, A.M., Platin, N., Kearney, N., Patiraki, E., 2005. Use of complementary and alternative medicine in cancer patients: a European survey. Annals of Oncology 16 (4), 655-663.
Molassiotis, A., Panteli, V., Patiraki, E., Ozden, G., Platin, N., Madsen, E., Browall, M., Fernandez-Ortega, P., Pud, D., Margulies, A., 2006. Complementary and alternative medicine use in lung cancer patients in eight European countries. Complementary Therapies in Clinical Practice 12 (1), 34-39.

Montazeri, A., Sajadian, A., Ebrahimi, M., Haghighat, S., Harirchi, I., 2007. Factors predicting the use of complementary and alternative therapies among cancer patients in Iran. European Journal of Cancer Care 16 (2), 144-149.

NCCAM, 2010. National Center for Complementary and Alternative Medicine. http:// www.nccam.nih.gov.

Oh, E.G., 2004. Symptom experience in Korean adults with lung cancer. Journal of Pain and Symptom Management 28 (2), 133-139.

Persson, E., Wilde Larsson, B., 2005. Quality of care after ostomy surgery: a perspective study of patients. Ostomy Wound Management 51 (8), 40-48.

Rabin, R., de Charro, F., 2001. EQ-5D: a measure of health status from the EuroQol Group. Annals of Medicine 33 (5), 337-343.

Richardson, M.A., Masse, L.C., Nanny, K., Sanders, C., 2004. Discrepant views of oncologists and cancer patients on complementary/alternative medicine. Supportive Care in cancer 12 (11), 797-804.

Richardson, M.A., Sanders, T., Palmer, J.L., Greisinger, A., Singletary, S.E., 2000. Complementary/alternative medicine use in a comprehensive cancer center and the implications for oncology. Journal of Clinical Oncology 18 (13), 2505-2514.

Salander, P., Henriksson, R., 2005. Severely diseased lung cancer patients narrate the importance of being included in a helping relationship. Lung Cancer 50 (2), 155-162.

Saydah, S.H., Eberhardt, M.S., 2006. Use of complementary and alternative medicine among adults with chronic diseases: United States 2002. Journal of Alternative \& Complementary Medicine 12 (8), 805-812.

Schmidt, K., Ernst, E., 2004. Assessing websites on complementary and alternative medicine for cancer. Annals of Oncology 15, 733-742.

Sirois, F.M., Gick, M.L., 2002. An investigation of the health beliefs and motivations of complementary medicine clients. Social Science \& Medicine 55 (6), 1025-1037.

Thorne, S., Paterson, B., Russell, C., Schultz, A., 2002. Complementary/alternative medicine in chronic illness as informed self-care decision making. International Journal of Nursing Studies 39, 671-683.

Tishelman, C., Lundgren, E.L., Skald, A., Tornberg, S., Larsson, B.W., 2002. Quality of care from a patient perspective in population-based cervical cancer screening. Acta Oncologica 41 (3), 253-261.

Tishelman, C., Lövgren, M., Broberger, E., Hamberg, K., Sprangers, M., 2010. Are the most distressing concerns of patients with inoperable lung cancer adequately assessed? A mixed-methods study. Journal of Clinical Oncology 28 (11), 1942-1949.

Vincent, C., Furnham, 1996. Why do patients turn to complementary medicine? an empirical study. British Journal of Clinical Psychology 35, 37-48.

Wilde-Larsson, B., Larsson, G., 2009. Patients' views on quality of care and attitudes towards re-visiting providers. International Journal of Health Care Quality Assurance 22 (6), 600-611.

Wilde, B., Larsson, G., Larsson, M., Starrin, B., 1994. Quality of care. Development of a patient-centred questionnaire based on a grounded theory model. Scandinavian Journal of Caring Sciences 8 (1), 39-48.

Wilde, B., Starrin, B., Larsson, G., Larsson, M., 1993. Quality of care from a patient perspective-a grounded theory study. Scandinavian Journal of Caring Sciences $7(2), 113-120$.

Wilde Larsson, B., Larsson, G., 2002. Development of a short form of the Quality from the Patient's Perspective (QPP) questionnaire. Journal of Clinical Nursing 11 (5), 681-687.

Wilde Larsson, B., Larsson, G., Wickman Chantereau, M., Stael von Hlostein, K., 2005. International comparison of patients' views on quality of care. International Journal of Health Care Quality Assurance 18 (1), 62-73.

Yardley, S.J., Davis, C.L., Sheldon, F., 2001. Receiving a diagnosis of lung cancer: patients' interpretations, perceptions and perspectives. Palliative Medicine 15 (5), 379-386. 